\title{
Negotiating Urban Redevelopment: Exploring the Neighborhood Council
}

\section{Planning Model}

Gillad Rosen

Nufar Avni*

Department of Geography, The Hebrew University of Jerusalem, Mt. Scopus ,Jerusalem 91905

Tel: $972-2-5883344$

*Corresponding author: nufar.avni@mail.mcgill.ca

\section{Key Words [4-5]}

Just planning, Community planning, Redevelopment, Jerusalem, Neighbourhood Councils

\begin{abstract}
This paper analyzes the redevelopment of a residential compound in Jerusalem from a justice perspective. It focuses on the role of the Neighbourhood Council (NC) in negotiating representation and recognition of local residents in the planning process. Based on analysis of interviews, planning documents, focus group meetings, and court appeals, we argue that as a hybrid governance structure, which mediates between the residents and the municipality, the NC is uniquely positioned to promote more just and inclusive planning process and outcomes at the neighbourhood scale. However, the NC still faces substantial challenges due to its intermediary position.
\end{abstract}




\section{Introduction}

In the last few years, the residential Ganim quarter in Jerusalem's South West has been undergoing rapid change. Urban redevelopment projects, the biggest the city had seen so far, are being planned there- raising contentions between the Neighborhood Council (NC henceforth) and the municipality regarding how they view these changes. From the municipality's perspective, urban redevelopment is perceived as a powerful instrument to intensify built-up areas, rebrand seemingly declining neighborhoods, and inject capital into underinvested spaces such as the Ganim quarter. From the NC's viewpoint, however, redevelopment could also mean tailoring the area to the needs of more affluent residents at the expense of marginalized ones, and is subjecting the latter to unjust social outcomes - a view supported by academic scholarship (Hackworth and Smith 2001; August 2016; Davidson and Lees 2010; Hyra 2015; Avni 2017).

The interplay of governments, residents, and more lately, developers, in the controversial process of redevelopment has long been a subject of academic inquiry (Porter and Shaw 2013; Geva and Rosen 2018; August and Walks 2017; King and Lowe 2018; Kuyucu and Ünsal 2010). This paper seeks to expand the traditional 'triangle' of redevelopment stakeholders by focusing on the role of a fourth and less discussed one: The NC in Jerusalem. In a country dominated by a three-tier centralized planning system such as Israel (Eshel and Hananel 2019), the Jerusalembased NC is a unique decentralized planning model that largely draws on local representationequivalent structures do not exist in other Israeli cities. The NC is a local governance agency funded and administered by the municipality but is representative of the residents of the borough in which it is located. Situated in an intermediary position, the interests of the NC may align with, or contradict, the municipality's agenda. Our analysis exemplifies the NC's challenging role through a case study of a recently approved housing redevelopment. The Jerusalem 
Municipality promotes plans to raze and rebuild the Nurit compound — an impoverished former public housing site located at the urban fringe-as a mixed land-use and income community.

This paper examines the role of the NC in the Nurit redevelopment, emphasizing the tensions that are in play in the revitalization of a socially and economically deprived area. Existing literature has considered the general characteristics of NCs and their prescribed roles in fostering trust and enhancing the social and political capital of neighborhood residents (Park, Mosley, and Grogan 2018; Anderson, Blair, and Shirk 2018). Yet only limited research has empirically analyzed their actual practices and the role they play in urban governance (Jun and Musso 2013; Lelieveldt et al. 2009; Fontan et al. 2009). Even less research has examined their involvement with urban redevelopment processes, particularly in the non-US/British context. We begin to fill this gap through the Nurit case. We argue that the NC strives to achieve a more equitable redevelopment path than the one typically prescribed by the government, addressing both redistribution and recognition (Fraser 1995) by advocating for the needs of the marginalized residents, and by securing local public interests more generally. Nonetheless, the NC can also be criticized for not representing all voices in the neighborhood and advancing the narrow interests of highly educated and involved activists (Avni 2019; Park, Mosley, and Grogan 2018; Zaban 2019).

We argue that despite its conflicted position, 'caught' in-between various groups of residents and the municipality, the NC's involvement presents a model for advancing just neighborhood planning, which attempts to balance the desire to develop with securing the community's needs. At the same time, the NC is challenged locally and put under tremendous pressure; first by its limited resources, second by its delicate position in relation to the municipality that funds its activities, and third by its contested legitimacy among some residents 
who perceive its actions as an unnecessary and even manipulative interference with their interests. While the NC gained only limited success in this specific struggle, important lessons are drawn concerning its capabilities and needs in future redevelopments. Our analysis suggests that strengthening the NC's role and equipping it with further authority could potentially lead to more just redevelopment outcomes in the future. At the same time, the NC's decision-making processes must be made more transparent and representative of diverse voices to enhance its legitimacy among residents.

The paper starts with a literature review on the role of NCs in urban governance, situating the Jerusalem case within broader debates about participatory and just planning. In the subsequent sections, we explain the research methods and provide the context for the case study through a brief introduction on "raze and rebuild" projects in Jerusalem, as well as the city's existing model of community planning and NCs. In the discussion part, we outline the redevelopment case from the main stakeholders' perspective and discuss the main planning phases and intervention attempts. Finally, we present the relevance of the Jerusalem case to wider scholarship on urban redevelopment and social justice. We conclude that the NC is wellpositioned to advance both redistribution and recognition for the ethnically and socially-mixed communities of the Nurit Compound. However, as an intermediary agent, the NC is situated between a rock and a hard place and is challenged by structural and internal constraints.

\section{The role of Neighborhood Councils in participatory urban governance}

Neighborhood Councils function in various forms across diverse geographical locations. Their different names_-neighborhood associations/ organizations, community organizations, or community development councils_-reflect differences in their political role, composition, funding arrangements, and administrative structures. NCs can be formed from 'above' or 
'below': whereas some can be considered as grassroots organizations since they are non-profit, volunteer-run (Smith 2000), others receive funding from municipalities and are anchored in topdown institutionalized settings (Kathi and Cooper 2005). The roles of NCs and their domains of engagement are also diverse and include land-use, health, economic development, safety, public services, and more (Jun and Musso 2013; Durose and Lowndes 2010). These differences make a comparison of NCs across different countries challenging (Stoecker 1997).

Nonetheless, NCs have important common features that make such a comparison valuable; they are an intermediary body placed between the local government and communities (Coaffee and Healey 2003; Yinon-Amoyal and Kallus 2005), they have "a leadership role to play in the urban decision-making process" (King 2004, 391), and are uniquely positioned to influence city policies on a neighborhood scale. In theory, they enable greater participation of residents in neighborhood affairs and form an important part of civil society, increasingly becoming more insistent about participating in policy-making (Bailey 2012). Still, others emphasize that their success hinges on financial and administrative concerns (Park, Mosley, and Grogan 2018).

Some scholars, however, are not optimistic about the potential of community councils to pursue local transformations, much less about their ability to do so equitably. Purcell (2006) argues that the literature about local governance tends to assume that the local is preferable to other scales without sufficient evidence to support this belief — which he terms the 'local trap.' Fainstein (2010), while in general supportive of the local governance scale, clarifies that although local knowledge is important and likely contributes to more democratic decisionmaking, the planning outcomes may not necessarily be more equitable due to public participation alone. A classic example of how the local scale might interfere with larger societal interests is 
the not-in-my-backyard (NIMBY) phenomenon, where residents and/or associations object to the placement of facilities or services in proximity to their homes, despite the facilities' benefits to the wider community (see Buckman 2011; Schively 2007). In many cases, NIMBYism is carried out by relatively privileged and wealthy residents who have the time and means to promote their agenda, which may disregard the needs of less privileged ones. By the same token, NCs may represent the interests of the more powerful constituencies, elites or small proactive groups of residents and volunteers, which neither represent nor account for the needs of less engaged groups that live in the neighborhood (Avni 2019; Park, Mosley, and Grogan 2018; Zaban 2019).

However, a detailed study of NCs in Los Angeles finds that the relationship between their activities and the socio-economic profiles of their respective neighborhoods was not clearcut. Contrary to the common assumption that NCs prioritize the interests of middle-class property owners, "lower-income communities also employ these venues to prevent the burden of locally undesirable land uses" (Jun and Musso 2013, 98; see also Singer and Rosen 2019). Moreover, the authors argue that viewing these organizations as classic NIMBYism would be inaccurate since many of them undertook deliberative and inclusive processes - rendering them meaningful mediating institutions. Another recent study finds that in the marginalized communities of Chicago's south side, neighborhood organizations were perceived as more legitimate than elected officials (Park, Mosley, and Grogan 2018). The Jerusalem case will be used to assess the tensions that exist between the potential of the NC model to enable civic engagement and the challenges to achieving this on the ground.

\section{Just urban governance}

In the last decade, there has been a renewed interest in equity planning and social justice

(Fincher and Iveson 2012; Marcuse et al. 2009; Avni and Fischler 2019; Zapata and Bates 2015). Questions of who decides what is just, and what is the role of planners in promoting justice, have 
once again appeared as central issues in planning theory (Reece 2018; Lake 2017). While the literature about NCs encompasses issues of representation, democracy and participation, which can be considered components of justice, most studies to date have not examined participatory local governance from a justice perspective. We suggest to analyze the role of the NC from this angle, and particularly through Nancy Fraser's (1995, 1998; Fraser and Honneth 2003) conceptualization of justice. Fraser builds on both material and non-material aspects of justice, asserting that both recognition and redistribution are fundamental components of it. With regards to redistribution, she recognizes that a just society entails a just distribution of resources and goods. However, she argues that injustices that result from misrecognition cannot be remedied by redistribution alone (Fraser 1995). Thus, recognition and distribution relate to each other but are analytically separate.

Another influential conceptualization of justice in the last decade has been Susan Fainstein's (2010) Just City framework. Fainstein defines justice as composed of three pillarsequity, democracy, and diversity — which she then tests in New York, Amsterdam, and London. One of Fainstein's goals has been to retract from what she considers as over-emphasis on procedural aspects of planning in favor of a greater emphasis on policy outcomes. In her interpretation of democracy, Fainstein stresses broad participation and deliberation in decisionmaking processes, as well as the representation of various groups in the city, including marginalized ones. Yet while she acknowledges that participation in the planning process is important to represent multiple interests, she sees it as a means to an end, and in her view, equity takes precedence over democracy.

So far, many studies on redevelopment and justice have focused on either the 'planners' — government employees or planners working for nonprofits—or the 'planned'—such 
Journal of Planning Education and Research. First Published November 15, 2019

https://doi.org/10.1177/0739456X19884100

as residents or community organizations. However, this binary does not capture the hybrid governance structure examined in this paper, the NC, which is composed of both elected representatives from the neighborhood—active residents who seek to represent their communities - and professional appointments. In the following sections, we analyze the redevelopment plan for the Nurit compound building on the notions of representation, diversity, recognition and redistribution and how they manifest in the NC's role, thus adding a new perspective to this rich scholarship.

\section{Methods}

We explore the process of urban redevelopment in a deprived community, specifically examining the influence of the NC on the planning outcomes. We analyze the NC's role from a justice perspective, drawing on Fraser's (1995, 1998) and Fainestein's (2010) conceptualizations. While their definitions remain fairly broad (Avni and Fischler 2019), we refer to the following key categories in our analysis: democracy (representation of marginalized groups, consultation, community input); diversity (multiple voices, social, economic and ethnic mix); and equity (nondisplacement, affordability). These more specific categories relate to the meta-concepts of recognition and redistribution, as we will demonstrate in the discussion.

Our study draws on analyses of primary and secondary data. First, to understand development trends and policy framework, 44 semi-structured interviews with 35 key stakeholders interviewees were conducted during the years 2012-2019. Except for two phone interviews, the rest were conducted face to face. Interviewees were selected through targeting key stakeholders' groups, including public and private-sector planners, developers, politicians, NC members, residents, social activists, and NGO representatives (Appendix 1). We also build 
on informal conversations with neighborhood residents and community activists, whom we approached through our personal connections to the Ganim-Yuvalim quarter. We supplemented the interviews by observing six expert panels and public meetings in which the mayor, senior planners (regional and municipal), and social activists participated (Appendix 2).

Second, to understand the Nurit compound residents' perspective, we conducted a participatory observation in three focus group meetings led by a social worker in 2013 . These three groups of residents were considered to represent a diverse mix of people and interests. They included: (1) longtime residents (many of them are homeowners who purchased their properties from the state), (2) residents with a Jewish Orthodox religious background (some of them young families with children who had been seeking cheap housing opportunities), and (3) public housing residents (i.e. renters, many of whom are longtime residents). We conducted a participatory observation in two ad hoc NC meetings during 2015-2016, which included homeowners, private planning consultants (including attorneys and planners), and officials from Moriah - Jerusalem's development company that is in charge of urban regeneration across the city. Third, we reviewed demographic reports composed by municipal planners and by a coalition of institutions active in the neighborhood. Last, we examined planning documents, court appeals, and minutes of planning committee meetings.

\section{The local context: Community planning in jerusalem}

Jerusalem's planning trajectory has been strongly influenced by the city's contested geopolitics and the exclusion of its East Jerusalemite Palestinian residents (Shtern and Yacobi 2019; Nitzan-Shiftan 2017). Many planning decisions are made at the national scale due to the city's prime geopolitical importance (Bar 2019). The subordination of local planning to ethno- 
national aspirations has also influenced more ordinary municipal decision-making procedures, for example, the lack of a formal statutory Master Plan that would provide residents some certainty as well as a voice in planning procedures. This condition, also referred to as a democratic deficit (Rosen and Charney 2018), has intensified due to the lack of true democratic debate and limited transparency in some planning procedures in Jerusalem (Jakar et al. 2018).

Against this background, the NC in Jerusalem plays an important role. It is an intermediary governance structure that mediates between the residents and the municipality (Hasson and Ley 1994). The rationale for its establishment was the need to manage a rapidly growing city, both in territory and demography, which was composed of myriad communities of different religions, ethnicities, and socio-economic strata. This need became more pronounced after the annexation of East Jerusalem and additional territories in 1967, which substantially increased the city's size in the course of a few days. The idea for the NC initially developed in the Department of Social Work at the Hebrew University, was adopted by Mayor Teddy Kollek as a pilot project in 1973, and later on modified and duplicated to the rest of the city (YinonAmoyal and Kallus 2005). According to Hasson \& Ley (1997, 37), under Mayor Kollek’s administration (1965-1993) the strategy was to encourage decentralization of social service delivery in order to "promote social harmony in a culturally divided city" as well as to ensure the legitimacy of the local state. In the 1970s, the city also established community centers that focused on the provision of cultural and sports facilities. Following some struggles over budgets and responsibilities, the two functions were united by the early 1990s. Since then, the NCs, 28 in total (Figure 1), have served both as institutions in charge of representing residents with regards to various municipal issues, as well as providers of recreational facilities (Bar-Ner 2016). 
The NCs operate in a hybrid, two-tier system: professional staff operates under the auspice of the Israeli Association of Community Centers. The second layer is a community council, which is an independent legal association performing under the 1980 Associations Law (Yinon-Amoyal and Kallus 2005). The NC follows a participatory democratic model: $60 \%$ of its management is elected by neighborhood residents, while the other $40 \%$ consists of institutional representatives. Accordingly, some functions are run voluntarily, yet others are supported by funds allocated by the municipality (Yinon-Amoyal and Kallus 2005). The role of the NC is to provide social services and to look after the residents' needs, primarily in the areas of culture and welfare, and to mediate between the municipality and the residents (Zaban 2016).

Since one of the goals of the NC is to encourage residents' participation in local governance, each NC employs an urban planner and a social worker. The NC's professional staff maintains direct contact with the city planners and is responsible for providing input on plans, informing the public on planning processes and representing their voice, surveying community needs, and leading projects for the benefit of the local public (Bar-Ner 2016). Urban planning is recognized as a significant arena through which the NCs effect change. At the same time, planners are usually hired on a part-time basis, which challenges their capacity to fulfill all of their diverse duties, especially long-term strategic planning (Interview with NC planner, 2016).

Moreover, the fact that the NCs are partly institutional bodies and partly community organizations creates inherent tensions for the planners and social workers, who must strike a balance between occasionally conflicting rationales (Lavee, Cohen, and Nouman 2018; Geva and Rosen 2016). As a chairperson of one NC explained, the municipality "sees us as service providers ... [and] would want us to remain with limited powers, i.e., at best inform residents on municipal initiatives" (Interview, 2018). Since they see themselves first and foremost committed 
to their local public, NCs have occasionally taken active stands against municipal planning schemes that did not align with their professional stance. While in the US or the Canadian Ward System a specific constituency is represented by locally elected council members, which often hold real power and influence over the planning arena (Rosen and Walks 2015), in Israel, development decisions and negotiations over local public goods remain at the municipal level (Alfasi and Ganan 2015). Furthermore, the idea of linking planning rights with benefits to local communities is, at best, loose (Margalit 2014). Nonetheless, the legitimacy of the NCs is not uncontested, since voting rates are often low and the elected members are not always considered representative of the population in terms of their ethnic and socio-economic background (Zaban 2016).

Figure 1: Map of Selected NCs in Jerusalem Source: Oz Zalel

\section{Jerusalem's experience with raze and rebuild}

Since the turn of the century, large-scale plans to upgrade the deteriorating built environment have assumed growing importance in the transformation of Jerusalem's urban landscape. The last decade has served the national government's aim of radically restructuring the planning arena and advancing neoliberal agendas in Israel (Charney 2017; Hananel 2017; Friedman and Rosen 2019; Yiftachel and Avni 2019; Feitelson 2018; Mualam 2018). In fact, urban redevelopment programs, in the form of 'raze and rebuild,' are currently being promoted throughout the country. Israel's Ministry of Construction and Housing states that the main goals 
of urban regeneration are to advance intensification by adding new residential units to existing areas and to upgrade urban infrastructure and public spaces (National Urban Renewal Authority 2019). In light of this agenda, the Jerusalem municipality has launched a citywide development policy that promotes redevelopment via a range of mechanisms including infill development, addition of new stories to existing buildings, and the execution of 'raze and rebuild' programs that substantially increase building densities (Rosen and Charney 2018).

Unlike regular plans, which must concur with approved master plans in a hierarchical three-tier planning system, raze and rebuild projects are prioritized and enjoy the extensive support of various government agencies, as well as special tax breaks and expedited approval (Geva and Rosen 2018). A central feature of these plans is that they are largely free of existing statutory density and land-use zoning restrictions. The number of units, building densities, and land-use zoning are therefore a product of negotiations between local authorities, central government agencies, developers, and property owners. This agenda represents a major shift from a long tradition of state-led assistance programs for housing renovations, neighborhood renewal, and housing assistance programs for disadvantaged communities (Carmon 1999; Hananel 2017). It reflects, instead, a neoliberal housing agenda based on private-public partnerships (Hackworth and Smith 2001; Uitermark and Bosker 2014; Goetz 2013; Blander, Moser, and Avni 2018; Margalit and Kemp 2019).

With approximately fifty sites in Jerusalem alone and with a carrying capacity of 17,000 new housing units, raze and rebuild schemes are perceived as an important mechanism that will assist in substantially increasing the housing stock, through the introduction of taller buildings with potentially new populations. More specifically, the 2015 outline plan for the GanimYuvalim urban quarter in West Jerusalem, home to the Nurit project, has been targeted as a high- 
priority area of urban regeneration. The head of the Yuvalim NC's physical planning committee noted that the area has been put under tremendous development pressures and will radically transform (Interview, 2018). The director of Jerusalem's Urban Regeneration Agency explained that 24 sites in the Ganim-Yuvalim quarter are designated for renewal, eventually quadrupling the housing stock and population of the area (Public lecture, 2018). The Nurit redevelopment thus carries important implications for future regeneration since it was essentially perceived as a pilot project to examine the feasibility of more extensive renewal programs, particularly in close vicinity of the Nurit project.

\section{The Nurit compound}

The Ganim and Yuvalim urban quarters comprise eight neighborhoods that are home to approximately 50,000 residents (Choshen et al. 2013) and are comparable to a small-medium sized city in Israel. This area was originally built to house immigrants and longtime residents of various social backgrounds. It has always been considered an eclectic environment, encompassing neighborhoods of diverse socio-economic strata and housing types. The Nurit street and its surrounding area are characterized by Le Corbusier-style six-to-ten-stories superblocks that were originally constructed as public housing. Built in the early 1960s, the area provided housing for socio-economically deprived Jewish immigrants and refugees from the Middle East and North Africa. Some of the residents have lived in these buildings for decades, raised their families there, and integrated into their respective communities. By virtue of its location, price and housing type, however, the Nurit Street remains a magnet for low-income communities, drawing immigrant Jews from Ethiopia and the former USSR since the mid-1980s: about a third of the housing units are owned by them. Thus, residents and property owners of the 
buildings are not one homogenous group but are split along various lines, including tenure, seniority, socio-economic status, and country of origin.

Over time, the neighborhood has suffered neglect, buildings have been poorly maintained, and infrastructure has severely deteriorated. In the last two decades, the upwardly mobile residents have moved out, and housing units have further deteriorated. Following a series of 'Right to Buy' initiatives in which local tenants could buy their homes at some discount, ninety percent of the units in the Nurit compound have been privatized to date, of which about half are owner-occupied, and half are privately rented. The remaining ten percent are public housing units owned by the State of Israel. The neighborhood's socioeconomic cluster is 7 (in a scale of 1-20, where 20 is the most affluent). The main age groups included in the redevelopment project are 22-40 and 41-60 years. The size of the 0-18 years group is smaller compared to the neighborhood (24\% versus $33 \%$ ) whereas the age group of 65 and older is large (18\% compared to $13 \%$ ) (Viapland and Ganim NC, n.d.). The Nurit redevelopment plan (also known as Park View plan number 101-0109876) aims to demolish three rundown former public housing estates (Figure 2) that include 100 residential units and redevelop the area as a mixed land-use compound, with 428 units.

Figure 2: One of three buildings in the Nurit compound designated for redevelopment. Source: Authors

Home-owners of the apartment units signed an agreement transferring the legal rights of their property to the developers. In return, homeowners will have acquired, by the end of the redevelopment process, larger and newer condo-units that are estimated to double in value. 
According to plans, construction of the new buildings will occur first, followed by transferring the original residents into their new condo-units: only then will the original buildings be demolished. This sequence of regeneration, namely, to first rebuild, then to allow residents to move into the new units, and finally to demolish the old buildings, would mitigate the disruption in residents' lives that is typical of most urban regeneration processes. However, as the next sections will reveal, even with this mechanism in place, the NC expressed significant concerns about the ability of low-income residents to stay in the neighborhood and benefit from the proposed redevelopment.

\section{Between a rock and a hard place: The NC's role in the redevelopment}

The regeneration of the Nurit compound has been portrayed by the municipality and the developers as a 'win-win' situation. In this ideal scenario, the city of Jerusalem fulfills its goals of regeneration of a deprived area; the developers get their share of the profit, as well as the backing of the municipality; and the residents trade their dilapidated apartments with new and bigger ones without being displaced from their neighborhood. Alternatively, they can sell their new units and move to more affordable areas. One could argue that both the city and the developers advanced notions of spatial and economic justice by way of offering the residents an opportunity to accumulate capital and improve their material and social environment. However, implementing a large-scale redevelopment in a low-income area also brings various types of risks and potential injustices, such as displacement of residents and dismantling of communities (Goetz 2013; August 2016; Davidson and Lees 2010). Even though residents of the Nurit compound are eligible for replacement housing, as we will explain in this section, especially low-income residents might still face difficulties in staying in the area after the redevelopment due to the changing nature of the neighborhood. The $\mathrm{NC}$ was attentive to these potential negative 
Journal of Planning Education and Research. First Published November 15, 2019

https://doi.org/10.1177/0739456X19884100

consequences, whereas the city and the developers' visions of renewal mostly focused on economic improvements.

As the city presented the redevelopment plan as a panacea for the neighborhood's deteriorating status, the NC foresaw some of the anticipated problems. Based on planning protocols, court appeals, and interviews, we identify three main issues that the NC recognized as key in its struggle to change the Nurit plan: 1) the ability of longtime residents to stay in the neighborhood post-redevelopment (diversity), 2) the unbalanced power relations between the developers and the residents and their effect on consent to the project (democracy), and 3) the impact of the plan on the neighborhood in terms of congestion, amenities, and services (equity). In its efforts to promote better planning and fairer outcomes for the residents, the $\mathrm{NC}$ also sought recognition and legitimacy among residents and the municipality alike.

\section{Diversity: The plan's effect on longtime residents}

The NC had anticipated that regeneration might economically benefit some of the residents, namely homeowners, who are expected to see their properties double in size and value. Indeed, some homeowners openly stated that they are not interested in returning to the neighborhood post-regeneration. Instead, they perceived it as an opportunity to leverage the value of their real estate investments or sell their units and move elsewhere (Focus group meeting, 2013). The NC also realized, however, that many renters will not be able to afford to live in the newly built compound since redevelopment will induce higher rents, increased local municipal taxes and new, substantial, maintenance fees. A private planner working with the city confirmed: "[intensification] will produce new neighborhoods in existing areas for new populations" (Interview, 2013, our emphasis). A developer working in the neighborhood explained that "many residents will have to leave the neighborhood. From the city's perspective, 
Journal of Planning Education and Research. First Published November 15, 2019

https://doi.org/10.1177/0739456X19884100

it is forbidden to acknowledge it, but it's a fact: residents will leave" (Interview, 2013). Hence, the $\mathrm{NC}$ was concerned that the plan will promote gentrification of the area and that the rhetoric used by the municipality — that redevelopment will advance social mix —is questionable. A planner working for a human rights NGO emphasized the dissonance that exists within the redevelopment discourse:

Raze and rebuild is seemingly a 'win-win,' but in reality, it is much more complex. The city is primarily interested in economics, while the social dimension is secondary. Residents are manipulated to believe it is a 'take it or leave it' [deal]. Renewal plans reflect privatization and shrinking state responsibility towards deprived residents of neglected neighborhoods" (Interview, 2014).

The NC was supportive of better living conditions for the residents, but at the same time maintained that new housing is not the only component that should be considered.

\section{Democracy: Unbalanced power relations}

Concerns were also raised about the nature of the planning process, which was 'topdown', and skewed in favour of the interests of the Jerusalem Municipality, developers and other government agencies, while residents have been largely expected to conform to their plans. As opposed to public housing redevelopments, housing in the Nurit street neighborhood had been already privatized and is occupied by home-owners and renters (only 10 percent of the units are public housing). As such, the developers must obtain signed approval of at least $70 \%$ of all property owners to proceed with the plan. At the time, developers were essentially unsupervised 
Journal of Planning Education and Research. First Published November 15, 2019 https://doi.org/10.1177/0739456X19884100

in their access to, and communication with, residents, and could offer them various benefits in return for their consent. Not all residents, however, possessed sufficient literacy skills to understand the complex legal contracts that required their consent. One home-owner criticized how some of the signatures were attained, noting that "[they] were obtained from people who can't read or write. Most of us did not seek the advice of lawyers before signing our consent. [The developers] were handing out treats: new televisions and washing machines" (Focus group meeting, 2013).

While the NC was not against redevelopment per se, it did object to what it considered a top-down, undemocratic planning process and to the lack of serious consideration of social issues. It was particularly concerned that economically-deprived residents had agreed to the redevelopment plan without fully realizing the terms of the legal contracts and the consequences of the project. It should be noted, however, that some residents were discontented with the NC's involvement. As reflected in the local planning committee's minutes (Jerusalem Municipality 2016) residents feared that the campaign to change the plan would end in its abolishment altogether, thus leaving the neighborhood to further decay. One home-owner announced "I support the project, it is a gift, I fear it'll be stopped," while another resident emphasized the buildings' deteriorating condition. There was an obvious difference in attitudes among residents of the project who strongly supported it, while residents of the surrounding areas filed objections and challenged the plan.

\section{Equity: Impact on the neighborhood}

Lastly, the NC argued that the plan promotes extremely intense densification without providing appropriate infrastructure for the rapid expansion of the neighborhood, such as 
transportation, educational facilities, and amenities. The NC also argued that some residents would face difficulties in paying the high maintenance costs of high-rise buildings, which will potentially result in 'vertical slums' in the future. As a private consultant commented, "These Towers of Babel are just like a Lego game, [but] the only thing that matters is [economic] multipliers. There are other considerations ... Residents will not afford living [there] and maintaining [them]...I call this a [population] transfer." (NC meeting, 2016). These arguments demonstrate that the $\mathrm{NC}$ was concerned about the quality of life and the redistribution of resources for the long term. While many residents focused on their potential individual benefits, especially a new spacious apartment, the NC considered the neighborhood as a whole.

\section{Negotiating a just redevelopment}

The Ganim NC adopted a proactive approach in an attempt to fight for what it perceived as a more equitable redevelopment. The NC advocated for a Social Impact Assessment of the compound in collaboration with a group of institutions active in the neighborhood, including Mosaica (The Center for Conflict Resolution by Agreement), the JDC (an organization offering aid to Jewish communities around the world), and the Ministry of Social Affairs and Social Services. While public meetings were taking place, the NC led a persistent campaign to change the original proposed plan of the Nurit compound. As a result of a series of meetings with the city planning staff, and followed by several appeals to the District Planning Committee, the NC, together with city officials and developers, negotiated a revised planning deal.

Expecting that the new units will be much more expensive to maintain, they reached a binding agreement where 20 out of the 428 newly planned units will be assigned for long-term rental. A trust fund linked to these revenues would be used to cover the maintenance fees of returning home-owners for 15 years. In addition, the developers decreased the size of the planned 
commercial space from 8,500 square meters to 2,500 , thus partially decreasing anticipated traffic congestion and freeing inner parking space. Furthermore, developers have committed to providing linked-development in the form of five daycare centers and two synagogues as public amenities. Last, the apartments' size mix was changed to also include smaller apartments that could be sold or rented out to less affluent households (NC Ganim vs Jerusalem District Planning Committee and Others 2016).

In retrospect, although the NC's appeals to the Jerusalem District Court were rejected, its actions resulted in the drafting of a memorandum that was signed in 2016 by the municipality's chief planner and the head of the Ganim NC. This memorandum reflects the result of informal negotiations between the District and municipal planners and leaders of the Ganim NC, following the advancement of a new and more extensive plan for the larger neighborhood, commonly known as the Larger Nurit Plan. Importantly, the agreement recognizes the NC's role as a major stakeholder in future redevelopment processes. It declares the significance of public participation and the need to consult with representatives of home-owners before any regeneration process could commence, and it recognizes the need to rebuild compounds in a way that will not overcrowd them. Finally, the memorandum acknowledges the need to support residents in-need by renouncing maintenance fees of home-owners for the first five years postdevelopment (Moriah Jerusalem Development Corporation 2016).

\section{Between equity and democracy: Discussion and concluding notes}

Using the Nurit redevelopment case, we examined the role of the Ganim NC, Jerusalem, in local governance. Our case contributes to knowledge about NCs, urban redevelopment, and urban justice in several respects. First, we expand the focus on traditional redevelopment 
stakeholders - residents, developers, and governments - to include an additional hybrid actor, the NC, whose role has been little explored in this context. Second, while NCs have been examined from various perspectives, some related to urban justice, to the best of our knowledge, few studies have explicitly applied a justice framework to examine their actual practices. We argue that a justice lens is illuminative to critically examine the NC's actions and their implications for different stakeholders and on different scales. Third, we add more diversity to a literature consisting mainly of North American and British case studies. In the remaining part of this paper, we will draw our conclusions from the Jerusalem case.

First, some lessons can be learnt about the role of the NC in fostering just local governance. Urban redevelopment projects such as the Nurit case provide a valuable lens to examine just planning due to the confluence of (conflicting) interests and stakeholders that shape them (Avni 2019; Fainstein 2010). With regards to diversity and equity, we argue that the NC's input was critical in establishing mechanisms that will protect marginalized residents and encourage social mixing. These principles can also be thought of as recognition and redistribution (Fraser 1995). The NC sought to promote both just redistribution of resources-to private home-owners and renters alike - as well as to protect the identity of local communities, by advocating for solutions that would allow low-income residents, including home-owners, renters and public housing tenants, to stay in the area post-redevelopment. The NC realized that the distribution of new and better apartments for disadvantaged neighborhood residents would perhaps improve their material conditions, but without a holistic recognition of their needs, the plan could be problematic in the long run. According to the NC, those who wish to leave the neighborhood should have the opportunity to do so, but not at the expense of residents who wish to stay. Moreover, the NC pushed for direct neighborhood benefits in the form of infrastructure 
and amenities, thus providing a redistribution mechanism of public goods. The NC's course of action aligns with Fainstein (2010) concept of the Just City, where planners must keep in mind the (fair) outcomes of the planning process.

Second, with regards to issues of democracy and representation, akin to other studies, we posit that the intermediary role of the NC is both an advantage and a challenge. The Ganim NC did not oppose the redevelopment altogether, but it had major reservations about the ability of disadvantaged residents to remain in the area and the adequacy of the suggested infrastructure. Thus, the Jerusalem case should not be regarded as pure NIMBYism. As many scholars have pointed out, collaborative or participatory planning does not necessarily lead to real powersharing or a truly democratic decision-making process (Laurian 2009; Arnstein 1969), and this applies to NCs as well. Yet, while planning at the local level is not inherently more just than at the national scale (Fainstein 2010; Purcell 2006), our analysis suggests that the NC model has the potential to advance just planning. At the same time, some residents felt that the NC does not represent their interests and is putting the redevelopment at risk, thus perceiving its actions as illegitimate, patronizing, and manipulative. These feelings potentially exacerbated when the NC decided to pursue legal action against the municipality even after a deal with the developer had been struck, further eroding the NC's legitimacy among those who desired change.

In terms of the relationship between the $\mathrm{NC}$ and the municipality, we argue that the former is situated 'between a rock and a hard place.' On the one hand, the NC is perceived as a significant representative institution, but on the other hand, the municipality also tried to marginalize its role when their visions collided. Although the NCs were founded with a vision that positioned them in charge of participatory governance and local democracy (Zaban 2016), their status in the city is fragile and subject to constant erosion. For example, the Ganim NC's 
urban planner (as well as most other NCs) is employed on a part-time basis while being in charge of an area equivalent to the size of a small-medium sized city (50,000 people). This limitation hinders their ability to meaningfully shape planning processes.

In our view, the NC should be strengthened and provided with better means to take part in the ongoing social and physical production of the neighborhood. This means that the NC's toolkit for effecting change must be upgraded, including its ability to collect and analyze planning data, to better organize, train, and engage residents in planning processes and more generally in civic participation, and to be better positioned to influence municipal planning. At the same time, the NC must ensure that it becomes more transparent, and provide proper representation of diverse voices and interests.

\section{References}

Alfasi, Nurit, and Erela Ganan. 2015. “Jerusalem of (Foreign) Gold: Entrepreneurship and Pattern-Driven Policy in a Historic City." Urban Geography 36 (2): 157-80.

Anderson, Gary, Robert Blair, and Josh Shirk. 2018. "Neighborhood Associations and Community Development: Differences in Needs and Strategies." Community Development 49 (5): 504-21.

Arnstein, Sherry R. 1969. “A Ladder of Citizen Participation.” Journal of the American Institute of Planners 35 (4): 216-24.

August, Martine. 2016. “'It's All about Power and You Have None:' The Marginalization of Tenant Resistance to Mixed-Income Social Housing Redevelopment in Toronto, Canada.” Cities 57: 25-32.

August, Martine, and Allan Walks. 2017. “Urban Redevelopment.” In International Encyclopedia of Geography: People, the Earth, Environment and Technology, edited by 
Journal of Planning Education and Research. First Published November 15, 2019 https://doi.org/10.1177/0739456X19884100

Douglas Richardson, Noel Castree, Michael Goodchild, and A Kobayashi, 1-11. John Wiley \& Sons.

Avni, Nufar. 2017. “'So Long, and Thanks for All the Fish?' Examining the Built and Cultural Heritage of the Jaffa Port Redevelopment.” International Journal of Heritage Studies, 679_94.

—. 2019. "Bridging Equity? Washington DC's New Elevated Park as a Test Case for Just Planning." Urban Geography 40 (4): 488-505.

Avni, Nufar, and Raphaël Fischler. 2019. "Social and Environmental Justice in Waterfront Redevelopment: The Anacostia River, Washington, D.C.” Urban Affairs Review. Bailey, Nick. 2012. "The Role, Organisation and Contribution of Community Enterprise to Urban Regeneration Policy in the UK.” Progress in Planning 77 (1): 1-35.

Bar-Ner, Hilla. 2016. "The Neighborhood Council, Main Characteristics.” Street Language, 2016. https://www.stlanguage.com/\%d7\%94\%d7\%9e\%d7\%99\%d7\%a0\%d7\%94\%d7\%9c\%d7\%94\%d7\%a7\%d7\%94\%d7\%99\%d7\%9c\%d7\%aa\%d7\%99\%d7\%a7\%d7\%95\%d7\%95\%d7\%99\%d7\%9d-\%d7\%9c\%d7\%93\%d7\%9e\%d7\%95\%d7\%aa\%d7\%95/. (Hebrew)

Bar, Roni. 2019. "Shifting Borders, Shifting Center: Hedging-out Uncertainty in West Jerusalem's Urban Core.” Urban Geography, 1-21. https://doi.org/10.1080/02723638.2019.1613137.

Blander, Akiva, Sarah Moser, and Nufar Avni. 2018. "Religio-Nationalism and 'Soft Boundaries': Urban Gating in West Jerusalem and Tel Aviv.” Geoforum 96: 227-35. Buckman, Stephen T. 2011. 'Upper Middle Class NIMBY in Phoenix: The Community Dynamics of the Development Process in the Arcadia Neighborhood.” Journal of 
Community Practice 19 (3): 308-25.

http://www.tandfonline.com/doi/abs/10.1080/10705422.2011.595306.

Carmon, Naomi. 1999. "Three Generations of Urban Renewal Policies: Analysis and Policy Implications." Geoforum 30 (2): 145-58.

Charney, Igal. 2017. “A 'Supertanker’ Against Bureaucracy in the Wake of a Housing Crisis: Neoliberalizing Planning in Netanyahu's Israel." Antipode 49 (5): 1223-43.

Choshen, M, M Korach, I Doron, Y Israeli, and Y Assaf-Shapira. 2013. "Jerusalem: Facts and Trends 2013.” Jerusalem. (Hebrew)

Coaffee, Jon, and Patsy Healey. 2003. “My Voice: My Place': Tracking Transformations in Urban Governance." Urban Studies 40 (10): 1979-99.

Davidson, Mark, and Loretta Lees. 2010. "New-Build Gentrification: Its Histories, Trajectories, and Critical Geographies.” Population, Space and Place 16 (5): 395-411.

Durose, Catherine, and Vivien Lowndes. 2010. "Neighborhood Governance: Contested Rationales within a Multi-Level Setting - A Study of Manchester." Local Government Studies 36 (3): 341-59.

Eshel, Sharon, and Ravit Hananel. 2019. "Centralization, Neoliberalism, and Housing Policy Central-Local Government Relations and Residential Development in Israel.” Environment and Planning C: Politics and Space 37 (2): 237-55.

Fainstein, Susan S. 2010. The Just City. Ithaca: Cornell Univ. Press.

Feitelson, Eran. 2018. "Shifting Sands of Planning in Israel." Land Use Policy 79: 695-706.

Fincher, Ruth, and Kurt Iveson. 2012. "Justice and Injustice in the City." Geographical Research 50(3) (3): 231-41.

Fontan, Jean-Marc, Pierre Hamel, Richard Morin, and Eric Shragge. 2009. "Community 
Organizations and Local Governance in a Metropolitan Region." Urban Affairs Review 44 (6): $832-57$.

Fraser, Nancy. 1995. “Recognition or Redistribution? A Critical Reading of Iris Young's Justice and the Politics of Difference." Journal of Political Philosophy 3 (2): 166-80.

—. 1998. "Social Justice in the Age of Identity Politics: Redistribution, Recognition, and Participation.” In Working Paper, 98-108. Berlin: SSG Sozialwissenschaften, USB Köln. Fraser, Nancy, and Axel Honneth. 2003. Redistribution or Recognition?: A PoliticalPhilosophical Exchange. London New York: Verso.

Friedman, Rachel, and Gillad Rosen. 2019. "The Challenge of Conceptualizing Affordable Housing: Definitions and Their Underlying Agendas in Israel." Housing Studies 34 (4): $565-87$.

Geva, Yinnon, and Gillad Rosen. 2016. Community Work in Urban Regeneration: A New Model for Promoting Urban Justice. Jerusalem: Floersheimer Studies. (Hebrew)

—. 2018. "The Regeneration Deal: Developers, Homeowners and New Competencies in the Development Process." Geoforum 96: 10-20.

Goetz, Edward G. 2013. New Deal Ruins: Race, Economic Justice, and Public Housing Policy. Cornell University Press.

Hackworth, Jason, and Neil Smith. 2001. "The Changing State of Gentrification.” Tijdschrift Voor Economische En Sociale Geografie 92 (4): 464-77.

Hananel, Ravit. 2017. “From Central to Marginal: The Trajectory of Israel's Public-Housing Policy." Urban Studies 54 (11): 2432-47.

Hasson, Shlomo, and David Ley. 1994. Neighborhood Organisations and the Welfare Stat. Toronto: University of Toronto Press. 
—. 1997. "Neighborhood Organizations, the Welfare State, and Citizenship Rights." Urban Affairs Review 33 (1): 28-58.

Hyra, Derek. 2015. “The Back-to-the-City Movement: Neighborhood Redevelopment and Processes of Political and Cultural Displacement." Urban Studies 52 (10): 1753-73.

Jakar, Gidon S., Eran Razin, Mark S. Rosentraub, and Gillad Rosen. 2018. “Sport Facility Development: Municipal Capital and Shutting out the Private Sector.” European Planning Studies 26 (6): 1222-41.

Jerusalem Municipality. 2016. Minutes of Planning Sub-Committee 2016/11. Jerusalem: Office of Planning. (Hebrew)

Jun, Kyu Nahm, and Juliet Musso. 2013. "Participatory Governance and the Spatial Representation of Neighborhood Issues." Urban Affairs Review. 49 (1): 71-110.

Kathi, Pradeep Chandra, and Terry L. Cooper. 2005. "Democratizing the Administrative State: Connecting Neighborhood Councils and City Agencies.” Public Administration Review 65 (5): 559-67.

King, Lester O., and Jeffrey S. Lowe. 2018. “'We Want to Do It Differently’: Resisting Gentrification in Houston's Northern Third Ward." Journal of Urban Affairs 40 (8): 116176.

Kuyucu, Tuna, and Özlem Ünsal. 2010. "Urban Transformation as State-Led Property Transfer: An Analysis of Two Cases of Urban Renewal in Istanbul.” Urban Studies 47 (7): 1479-99. Lake, Robert. 2017. "Justice as Subject and Object of Planning." International Journal of Urban and Regional Research 40 (6): 1205-20.

Laurian, Lucie. 2009. "Trust in Planning: Theoretical and Practical Considerations for Participatory and Deliberative Planning." Planning Theory \& Practice 10 (3): 369-91. 
Journal of Planning Education and Research. First Published November 15, 2019 https://doi.org/10.1177/0739456X19884100

Lavee, Einat, Nissim Cohen, and Hani Nouman. 2018. "Reinforcing Public Responsibility?

Influences and Practices in Street-Level Bureaucrats' Engagement in Policy Design.” Public Administration, 96 (2): 333-348

Lelieveldt, Herman, Karien Dekker, Beate Völker, and René Torenvlied. 2009. “Civic

Organizations as Political Actors." Urban Affairs Review 45 (1): 3-24.

Marcuse, Peter, James Connolly, Johannes Novy, Ingrid Olivo, Cuz Potter, and Justin Steil. 2009. Searching for the Just City: Debates in Urban Theory and Practice. USA, Canada:

Routledge.

Margalit, Talia. 2014. "Multi-Spot Zoning: A Chain of Public-Private Development Ventures in Tel Aviv." Cities 37: 73-81.

Margalit, Talia, and Adriana Kemp. 2019. "The Uneven Geographies of Post-Political Planning:

Objections to Urban Regeneration Projects in Peripheral and Central Israeli Citie.”

Environmental and Planning A: Economy and Space. 51 (4): 931-949

Moriah Jerusalem Development Corporation. 2016. "The Nurit Street Memorandum. 24.07.2016.” (Hebrew)

Mualam, Nir. 2018. "Playing with Supertankers: Centralization in Land Use Planning in IsraelA National Experiment Underway." Land Use Policy 75: 269-83.

National Urban Renewal Authority. 2019. What Is Urban Regeneration? https://www.gov.il/he/Departments/Guides/about urban renewal. (Hebrew)

NC Ganim vs Jerusalem District Planning Committee and Others. 2016. "The Jerusalem District Court Sitting as the Administrative Court 36250-10-16.” (Hebrew)

Nitzan-Shiftan, Alona. 2017. Seizing Jerusalem: The Architectures of Unilateral Unification. Minneapolis: University of Minnesota Press. 
Park, Sunggeun (Ethan), Jennifer E. Mosley, and Colleen M. Grogan. 2018. "Do Residents of Low-Income Communities Trust Organizations to Speak on Their Behalf? Differences by Organizational Type." Urban Affairs Review 54 (1): 137-64.

Porter, Libby, and Kate Shaw. 2013. Whose Urban Renaissance?: An International Comparison of Urban Regeneration Strategies. London; New York: Routledge.

Purcell, Mark. 2006. "Urban Democracy and the Local Trap." Urban Studies. 43 (11): 19211941.

Reece, Jason W. 2018. "In Pursuit of a Twenty-First Century Just City.” Journal of Planning Literature, 33 (3):299-309

Rosen, Gillad, and Igal Charney. 2018. "Reaching New Heights: Post-Politicizing High-Rise Planning in Jerusalem." Built Environment 43 (4): 539-54.

Rosen, Gillad, and Alan Walks. 2015. “Castles in Toronto's Sky: Condo-Ism as Urban Transformation.” Journal of Urban Affairs 37 (3): 289-310.

Schively, Carissa. 2007. "Understanding the NIMBY and LULU Phenomena: Reassessing Our Knowledge Base and Informing Future Research.” Journal of Planning Literature 21 (3): $255-66$.

Shtern, Marik, and Haim Yacobi. 2019. "The Urban Geopolitics of Neighboring: Conflict, Encounter and Class in Jerusalem's Settlement/Neighborhood." Urban Geography, 40 (4): pp.467-487.

Singer, Matan E., and Gillad Rosen. 2019. "Rethinking Responses towards Group-Homes: Inclusionary Legislation, Supportive Municipal Attitudes, and Place-Based Opposition.” Social \& Cultural Geography 20 (3): 344-66.

Smith, D. H. 2000. Grassroots Associations. Thousand Oaks,Calif: Sage. 
Stoecker, Randy. 1997. "The CDC Model of Urban Redevelopment: A Critique and an

Alternative." Journal of Urban Affairs 19 (1): 1-22.

Uitermark, Justus, and Tjerk Bosker. 2014. "Wither the 'Undivided City'? An Assessment of

State-Sponsored Gentrification in Amsterdam."” Tijdschrift Voor Economische En Sociale

Geografie 105 (2): 221-30.

Viapland and Ganim NC. n.d. Implementing Social Considerations in an Urban Redevelopment

Project: The Nurit Stret Cimound. Unpublished report. (Hebrew)

Yiftachel, Oren, and Nufar Avni. 2019. “'Privati-Nation' - Privatization, Nationalization,

Housing and Gaps." Planning 16 (1): 225-247 (Hebrew).

Yinon-Amoyal, Einat, and Rachel Kallus. 2005. "The Neighborhood Council: Where 'Topdown’ Engages with ‘Bottom-Up.’” GeoJournal 64 (2): 91-104.

Zaban, Hila. 2016. "In the Name of Pluralism: Fighting the (Perceived) Ultraorthodox

Penetration in the Baka Neighborhood of Jerusalem.” Israel Studies 21 (3): 153.

—. 2019. "Whose Neighborhood Is It? On Belonging and Neighborhood Citizenship in the Baka Neighborhood of Jerusalem.” In Diversity and Turbulence in Contemporary Global Migration, edited by Natalie Jones Walthrust, 131-40.

Zapata, Marisa A, and Lisa K Bates. 2015. "Equity Planning Revisited.” Journal of Planning Education and Research 35 (3): 245-48.

This research was supported by the Israel Science Foundation (grant No. 789/15) and the Golda Meir Fellowship Fund at the Hebrew University of Jerusalem. 
Journal of Planning Education and Research. First Published November 15, 2019 https://doi.org/10.1177/0739456X19884100

Acknowledgements: We thank the anonymous reviewers and the editors for their constructive feedback. We also thank Rachel Friedman and Yinnon Geva for their valuable comments on an earlier draft of this paper and Oz Zalel for his help with the graphics of the paper.

Gillad Rosen is an associate professor in the Department of Geography and the director of the Institute of Urban and Regional Studies at the Hebrew University of Jerusalem. His research explores issues of urban governance, housing policy, energy and social ju stice.

Nufar Avni is a Marie Skłodowska-Curie Fellow at the Department of Geography at the Hebrew University of Jerusalem. Her research concerns the role of justice and equity in planning policies, urban redevelopment, urban citizenship, and planning in contested spaces. 